\title{
Effect of the Switching Times on the Operating Behavior of a Shockless Explosion Combustor
}

\author{
Fatma C. Yücel, Fabian Völzke and Christian O. Paschereit
}

\begin{abstract}
In the past, a wide range of investigations are made in order to increase the efficiency gain in gas turbines by using constant volume combustion. In comparison to detonation-based concepts, such as pulse detonation engine and rotation detonation engine, a new promising way was proposed by Klein and Paschereit and firstly assessed by Bobusch et al. (Combust Sci Technol 186(10-11):1680-1689 (2014), [1]), the so-called shockless explosion combustion (SEC). The principle is based on a quasi-homogeneous auto-ignition process that leads to an approximate constant volume combustion (aCVC). In order to achieve a quasi-homogeneous auto-ignition, it is necessary to achieve constant ignition delay times along the combustor. The combustion process in the SEC is similar to the one in internal combustion engines, namely Homogeneous Charge Compression Ignition (HCCI). This paper focuses on the use of wastegates to actively control filling and flow motion in the combustor dedicated to perform quasi-homogeneous auto-ignition. The results clearly show the ability to actively control the fuel distribution and purging time in the combustor which is an important step in the evolution of the SEC.
\end{abstract}

Keywords Constant volume combustion - Shockless explosion combustion Ignition delay time $\cdot$ Purging time

\footnotetext{
F. C. Yücel $(\varangle) \cdot$ F. Völzke · C. O. Paschereit Technische Universität Berlin, Institut für Strömungsmechanik und Technische Akustik, Müller-Breslau-Str. 8, 10623 Berlin, Germany e-mail: f.yuecel@tu-berlin.de

F. Völzke

e-mail: fabian.voelzke@tu-berlin.de

C. O. Paschereit

e-mail: oliver.paschereit@tu-berlin.de 


\section{Introduction}

Today, the potential of achieving a notable gain in gas turbine efficiency by improving components such as compressor or turbine is only incremental. A leapfrogging step could be achieved by replacing the conventionally utilized Brayton cycle (ideal constant-pressure cycle) by the Humprey cycle (ideal constant-volume cycle) [2] In the past decades, different concepts on this topic were investigated, e.g., pulsed detonation combustors (PDC) [3] and rotation detonation combustors (RDC) [4]. The PDC and RDC are both based on periodic combustion processes that utilize a detonation wave to achieve an approximate constant volume combustion (aCVC). By igniting a flammable mixture a detonation wave is initiated that propagates with a high velocity into the unburned mixture, the gas has no time to expand and burns quasi-instantaneously. However, detonation waves are inefficient due to sharp pressure peaks that are associated with strong losses. The shockless explosion combustor suggested by Bobusch et al. [1] is a new promising way to implement an aCVC to achieve an increase in the efficiency of a gas turbine cycle. The combustion process itself is similar to the HCCI process used in internal combustion engines [5, 6]. In the HCCI a homogeneous ignitable mixture is compressed until auto-ignition occurs while the SEC achieves a quasi-homogeneous auto-ignition by stratifying the fuel-air mixture along the combustor close to auto-ignition conditions. The fuel stratification is needed in order to compensate the residence time of the fuel such that a constant ignition delay time along the combustor is achieved. One challenge in the HCCI process is the ignition timing. The occurrence of too early or late combustion turned out to be disadvantageously for the HCCI process. For this, closed-loop control is applied to actively control the ignition timing. One similar challenge in the evolution of the SEC process is to control the ignition timing along the combustor to increase homogeneity of the auto-ignition process.

The SEC is based on a periodic combustion cycle that achieves an aCVC by a quasi-homogeneous auto-ignition process as shown in (Fig. 1). At the beginning of the process (Fig. 1, top), the combustor is filled with a well-defined stratified fuelair mixture. This axial stratification leads to a quasi-homogeneous auto-ignition of the entire gas volume after a certain ignition delay time. Due to the simultaneous combustion, a pressure wave is induced that propagates in downstream direction. At the open end of the combustor, the pressure wave is reflected as a suction wave that travels upstream (Fig. 1, bottom). As the suction wave reaches the tube inlet, the pressure drops below supply pressure and the recharge cycle can start. First, the combustor is purged with pure air creating a buffer to the hot combustion products. After a certain purging time, fuel is injected and the combustor is filled with the axially stratified fuel-air mixture (Fig. 1, left) while the suction wave is reflected and propagates downstream the tube. The suction wave is then reflected at the tube outlet as a pressure wave traveling upstream again. The process is restarted by another simultaneous combustion of the fuel-air mixture.

The ignition delay time of a mixture depends on temperature, pressure, equivalence ratio and the type of fuel and oxidizer. When assuming all other parameters to 


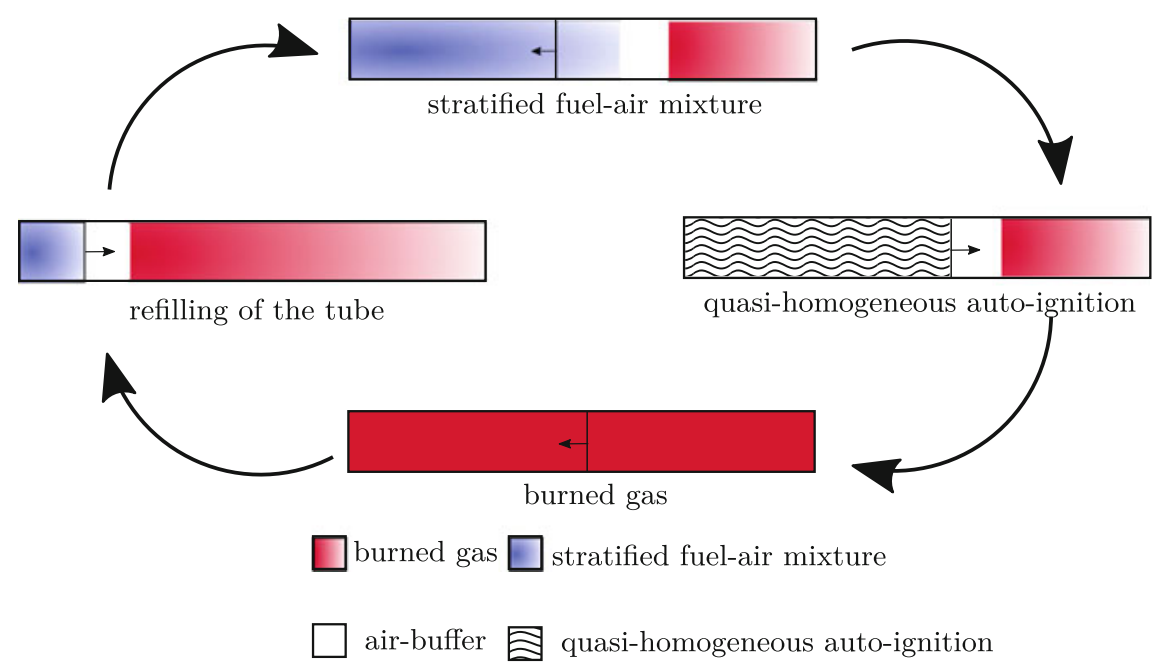

Fig. 1 SEC cycle

be constant, the spatial distribution of the ignition delay time $\tau(x)$ can be controlled by a stratification of the equivalence ratio. The ignition delay time decreases with increasing temperature, pressure and with decreasing deviation from stoichiometric conditions. Neglecting small temperature differences along the tube, a constant fuel injection would lead to an early ignition at the rear end of the combustor which would impede a quasi-homogeneous auto-ignition. In order to achieve a quasi-simultaneous auto-ignition, the ignition delay time must increase from the injection position to the outlet of the combustor. Further investigations have shown that a criteria for a quasisimultaneous ignition along the combustor is that the difference in ignition delay time $\Delta \tau_{\text {ign }}$ between two neighboring infinitesimal small volumes should not exceed the excitation time $\tau_{\text {et }}$, which is a value for the rate of chemical energy release $[7,8]$ :

$$
\Delta \tau_{\text {ign }} \stackrel{!}{<} \tau_{\text {et }}
$$

One challenging task is the realization of resonant operation. The frequency of the SEC cycle is determined by the acoustic frequency of the combustor-as it relies on the suction wave to initiate the refill process-which is in the order of $100 \mathrm{~Hz}$. For this, depending on tube length and speed of sound, very short ignition delay times are required. For atmospheric pressure conditions this can not be achieved, as the ignition delay times of all known fuels are not small enough. This crucial question gives room for future investigations and is not in the scope of this paper.

Another challenge is maximizing the gain in efficiency by achieving a quasihomogeneous auto-ignition. Therefore, an increase in homogeneity of the combustion process is aimed since it goes along with an increase in efficiency. This requires efficient control of the axial fuel stratification to realize an operational SEC process. 
Investigations showed that the application of an iterative learning controller into a closed-loop control is a promising way to minimize the variance of the ignition time by controlling the spatial fuel distribution [9].

For further improvements of the homogeneity of the auto-ignition, it is important to gain a deeper knowledge of this procedure and to analyze the impact of different input parameters. Two parameters are investigated in this work: the ability to control the spatial distribution of the fuel concentration and the impact of temperature fluctuations due to the purging time of the combustor.

\section{Experimental Setup}

An atmospheric test rig (Fig. 2) is designed to investigate the behavior of a shockless explosion combustor at non-resonant conditions. The test rig has been used in earlier investigations [9] and was modified in order to increase the experimental reproducibility.

The air is preheated to a maximum temperature of $700{ }^{\circ} \mathrm{C}$ using an electrical air heater to realize lowest ignition delay times. Dimethylether (DME) is used as fuel which exhibits an ignition delay time of around $100 \mathrm{~ms}$ at the given atmospheric pressure conditions and high temperatures [1, 10]. Additionally, DME has a characteristic small ignition delay time variation with temperature. Fuel lines are preheated to $90^{\circ} \mathrm{C}$ preventing liquification of the DME.

The application of the preheater requires a minimal mass flow of $30 \mathrm{~kg} / \mathrm{h}$. This results in a combustor flow velocity of about $22 \mathrm{~m} / \mathrm{s}$ and a residence time in the range of $30 \mathrm{~ms}$. With an ignition delay of $100 \mathrm{~ms}$ the ignitable mixture would have already left the combustor before ignition. Enabling also tests under atmospheric pressure conditions a bypass is installed allowing the combustor flow to rest after charging. Currently, valves for turbocharged engine systems that can be controlled actively are used, called wastegates, replacing the previously used fluidic switch and valve

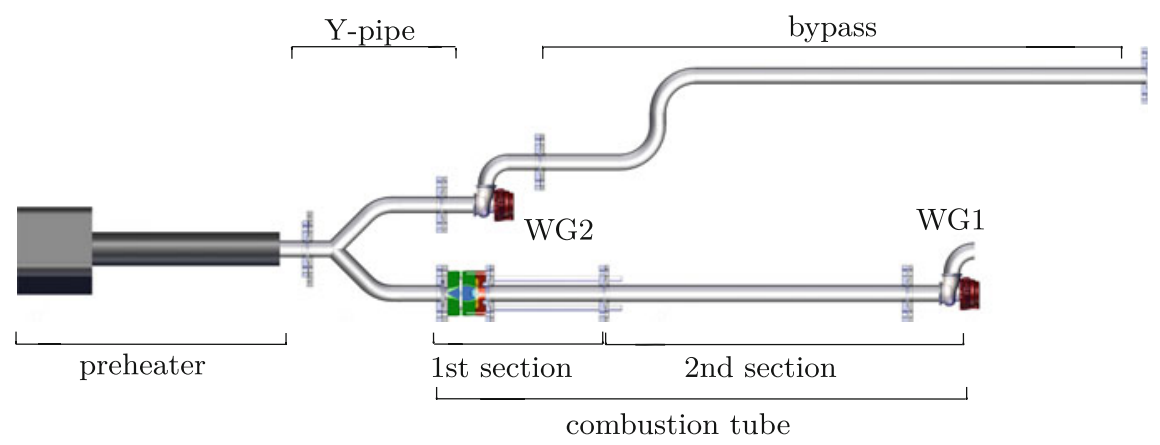

Fig. 2 Sketch of the modified atmospheric test rig of a shockless explosion combustor equipped with wastegates (WG) 


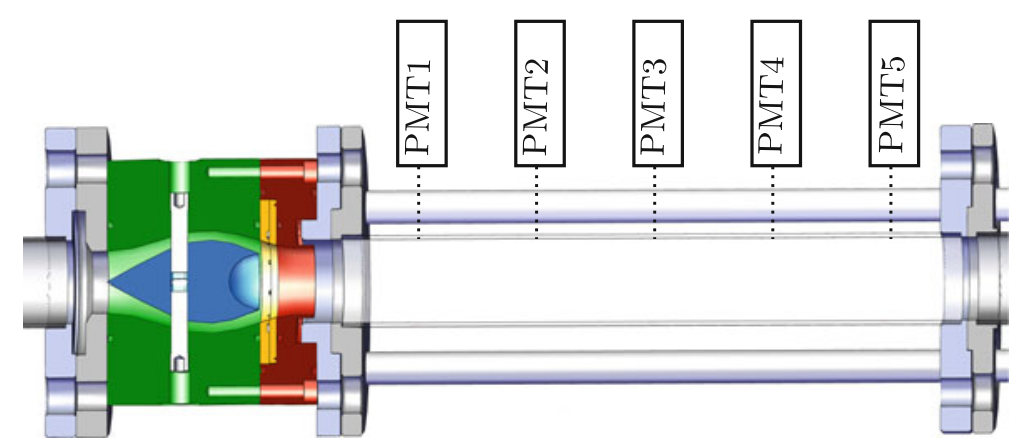

Fig. 3 Detailed view of the combustor with fluidic diode (blue) with oscillators (yellow), quartz tube and PMTs

heads. They have been installed respectively at the combustor (WG1) and at the bypass (WG2). These valves are equipped with several ports where boost pressure can be supplied such that they can be opened and closed actively. The advantage of these wastegates when compared to the fluidic switch in combination with valve heads is that the wastegates prevent backflow more reliably and the opening and closing timings can be adjusted actively. This has not been the case for the valve heads since they closed and opened passively depending on the pressure at the tube outlets. Furthermore, replacing the fluidic switch by a Y-pipe decreased the heat loss upstream of the combustor significantly.

A fluidic diode prevents the backflow of hot gases due to pressure increase after the combustion process and was already successfully used in earlier investigations [11]. The fuel is injected using two identical fuel injector arrays each equipped with four parallel-connected high-speed solenoid valves. The fuel inlet section is equipped with eight radial injection ports and fluidic oscillators to increase the mixing quality in the radial direction.

The combustor has two sections with an inner diameter of $d=40 \mathrm{~mm}$. The first section is made from a $0.5 \mathrm{~m}$ long quartz tube in order to enable the detection of the ignition event via photomultipliers (PMTs). These PMTs are used to evaluate the ignition delay times at five axial positions in the combustor (Fig. 3). The second part is a steel tube equipped with two water-cooled pressure sensors to detect the combustion-induced pressure wave.

\section{Investigation in the Wastegate Behavior}

The wastegates used in this work are composed of a main body and an actuator body (Fig. 4). The actuator body contains a piston that is connected to the valve head in the main body. There are two different ways of controlling control the wastegates: passive and active. Equipping the actuator body with springs of different spring constants, the 
Fig. 4 Sectional view of a wastegate; (1) valve head,

(2) boost pressure port for opening, (3) membrane, (4) boost pressure port for closing, (5) spring, (6) diaphragm

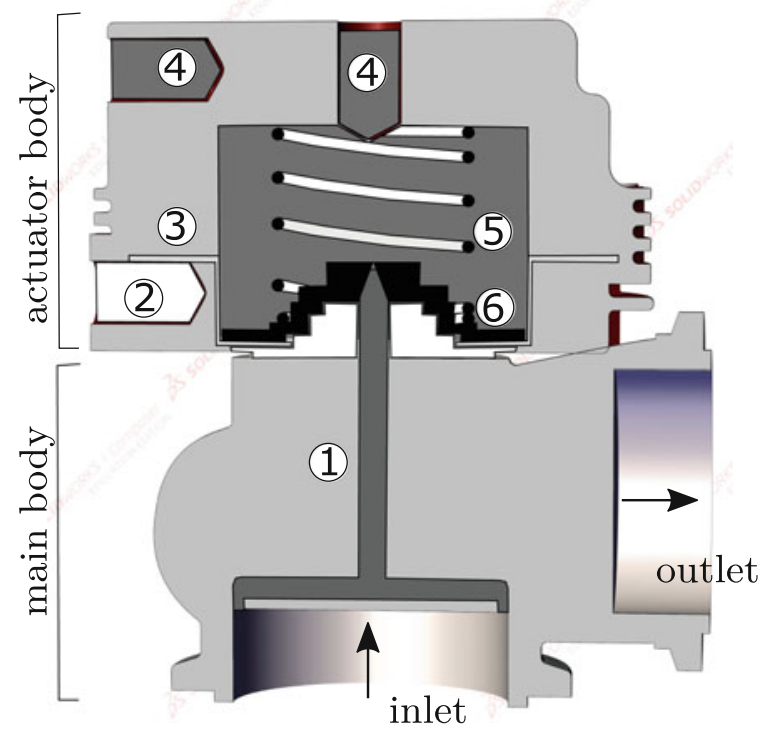

required input pressure for opening the valve can be controlled passively by setting the reset force of the piston. In this work, the wastegates were controlled actively by regulating the supplied boost pressure. A diaphragm separates the two different areas inside the wastegate for the boost pressure supply. By setting the pressure in the upper area to higher levels, the wastegate closes. When the pressure in the upper region is decreased and the pressure in the lower area is increased, the wastegate opens. 3/2-way valves have been applied to allow for controlling the boost pressure. It is important to note that the wastegate behavior and especially its response times are dependent on the operating speed of the $3 / 2$-way valves. One voltage signal is needed to operate both wastegates simultaneously since the 3/2-way valves are installed on each wastegate at inverted positions.

The switching process and its effect on the combustor flow was investigated using a laser Doppler anemometry system (LDA). This non-intrusive optical measurement technique enables a high spatial and temporal resolution. An aerosol (Bis(2ethylhexyl) sebacate) was used as seeding which was atomized using the aerosolgenerator.

The LDA measurements were done under non-reactive conditions using air only. The air flow has been set to $30 \mathrm{~kg} / \mathrm{h}$, which matches the conditions for reacting tests. The laser was positioned $50 \mathrm{~mm}$ downstream the injection geometry. Figure 5 displays the voltage signal for controlling the 3/2-way valves and the measured combustor flow velocity as a function of time for the first three periods at a switching frequency of $0.5 \mathrm{~Hz}$. When the air flow is guided to the combustor, the mean velocity measured was $u_{\text {mean }}=6.3 \mathrm{~m} / \mathrm{s}$ with an RMS-value of $u_{\mathrm{rms}}=0.68 \mathrm{~m} / \mathrm{s}$ implying a turbulence intensity of $10 \%$. When the voltage signal for controlling the 3/2-way valves is set to $U_{\mathrm{C}}=5 \mathrm{~V}$, WG1 closes and WG2 opens simultaneously. Subsequently, 
Fig. 5 Measured particle velocity $u$ with Laser Doppler Anemometry and switching signal $U_{\mathrm{C}}$ over time

Fig. 6 Mean velocity $u_{\text {mean }}$, RMS-value $u_{\text {rms }}$ and switching signal $U_{\mathrm{C}}$ over time
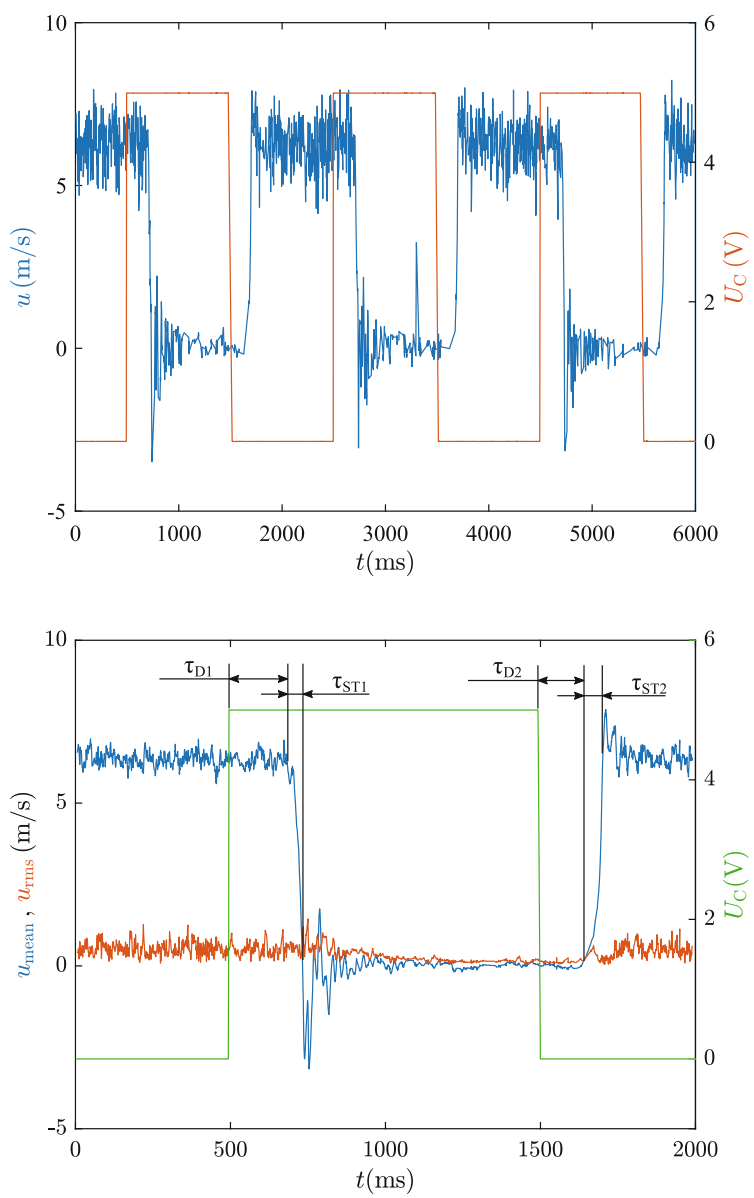

after a certain delay time the velocity decreases fast until the flow comes to rest. The main velocity is overlaid by velocity oscillations due to high turbulence during the opening and closing procedure. When the voltage signal is set back to $U_{\mathrm{C}}=0 \mathrm{~V}$, the flow velocity increases again until the mean velocity of $\bar{v}=6.3 \mathrm{~m} / \mathrm{s}$ is reached. Both switching events include two time delays respectively. To specify these time delay times, the velocity was averaged over 10 cycles and the delay times were assessed (Fig. 6).

The time delay for closing the WG1 is determined to be $\Delta \tau_{\mathrm{D} 1}=215 \mathrm{~ms}$, while the flow needs a time span of $\Delta \tau_{\mathrm{ST} 1}=17 \mathrm{~ms}$ to be decelerated to $u=0 \mathrm{~m} / \mathrm{s}$. The values for opening WG1 have been determined to be $\Delta \tau_{\mathrm{D} 2}=175 \mathrm{~ms}$ and $\Delta \tau_{\mathrm{ST} 2}=31 \mathrm{~ms}$. All values are listed in Table 1.

The RMS-value shown in Fig. 6 displays the stochastic fluctuations of the flow velocity when the air is guided through the combustor. The fluctuations between the cycles that appear when stopping the air flow in the combustor are very low which 
Table 1 Wastegate timings

\begin{tabular}{l|l|l}
\hline & WG1 closing (ms) & WG1 opening (ms) \\
\hline Wastegate delay $\tau_{\mathrm{D}}$ & 215 & 175 \\
Switching time $\tau_{\mathrm{ST}}$ & 17 & 31 \\
\hline
\end{tabular}

emphasizes the reproducibility of the switching events. Even though the flow cannot be stopped instantly, the reproducibility of the process enables the consistency of the stratification of the fuel-air mixture for reacting tests.

\section{Ignition Timing Measurements}

Preliminary investigations showed that the purging time can be actively controlled by triggering the wastegates. For this, the delay times discussed in the previous section (see Table 1) have to be taken into account. In this section, the impact of the actual wastegate timings and the purging time as an input control parameter on the combustion process of the SEC are evaluated under reacting conditions. The success rates for auto-ignition and the spatial distribution of the ignition delay time have been investigated as a function of the switching times. To investigate this behavior, a periodic non-resonant combustion process is applied.

One operational period of the SEC process can be divided into three different parts: charging, homogeneous ignition and purging. During the charging process, the air mass flow is guided through the combustor and a constant fuel mass flow is added for $30 \mathrm{~ms}$. Since this work focuses on the control aspect, the combustible mixture is not stratified as no homogeneous combustion is aimed here. After a well defined time span $\tau_{\mathrm{WT1}}$, that is varied between 40 and $120 \mathrm{~ms}$, the air flow is switched into the bypass by closing the wastegate WG1 and opening wastegate WG2. To specify the appropriate timing of the voltage signal, the time delays $\tau_{\mathrm{D} 1}$ and $\tau_{\mathrm{D} 2}$ are taken into account. While the mass flow is directed through the bypass, the ignition event takes place in the combustor. After a second defined time span $\tau_{\mathrm{WT} 2}$ the purging process starts by guiding the air flow through the combustor again. Thus, an increasing residence of the air mass flow in the bypass is equal to a decreasing purging time.

Figure 7 shows an exemplary period of a $1 \mathrm{~Hz}$ SEC cycle for $\tau_{\mathrm{WT} 1}=40 \mathrm{~ms}$ and $\tau_{\mathrm{WT} 2}=300 \mathrm{~ms}$. During the interval from 0 to $40 \mathrm{~ms}$ the air mass flow is guided through the combustor while fuel is injected at the same time from 0 to $30 \mathrm{~ms}$, such that the quartz tube is entirely filled with a flammable mixture. After $40 \mathrm{~ms}$ the closing procedure starts such that after the required switching time of $17 \mathrm{~ms}$ the wastegate is entirely closed and the air mass flow is guided through the bypass for a duration of $260 \mathrm{~ms}$. The air flow is then switched back into the combustor at $300 \mathrm{~ms}$ with an additional time delay of $31 \mathrm{~ms}$ until the end of the cycle. In total this induces a purging time of $669 \mathrm{~ms}$. 


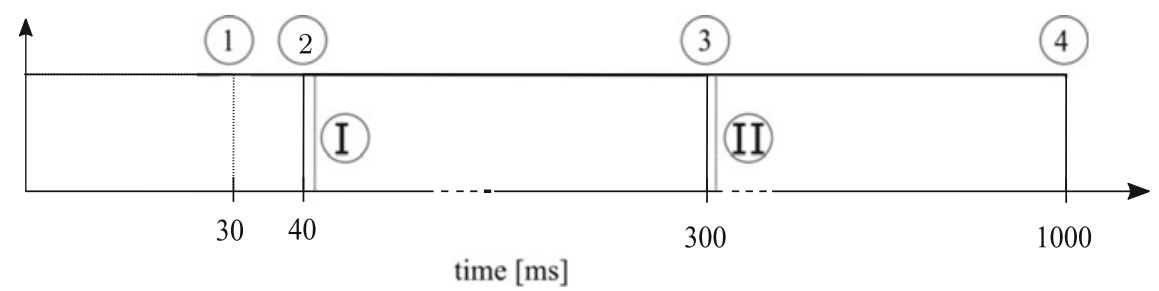

Fig. 7 Simplified representation of the different timings, (1) fuel injection time $\tau_{\text {inj }}$, (2) wastegate timing $\tau_{\mathrm{WT} 1}$, (3) wastegate timing $\tau_{\mathrm{WT} 2}$, (3) to (4) purging time $\tau_{\mathrm{pt}}$, (I) switching time $\tau_{\mathrm{ST} 1}$, (II) switching time $\tau_{\mathrm{ST} 2}$

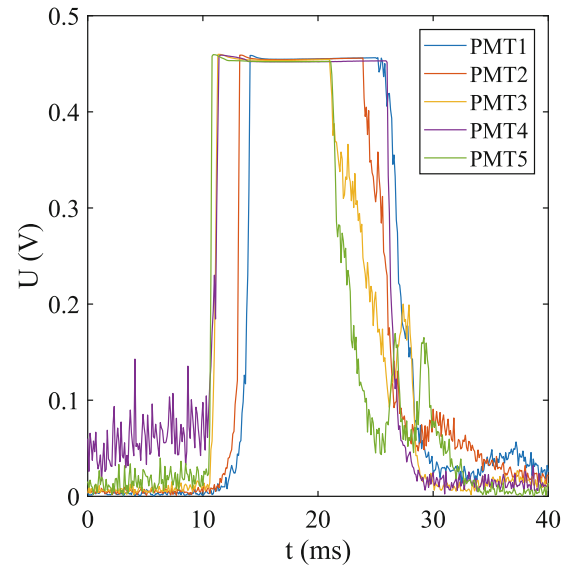

(a) $\tau_{\mathrm{WT} 1}=80 \mathrm{~ms}, \tau_{\mathrm{WT} 2}=690 \mathrm{~ms}$

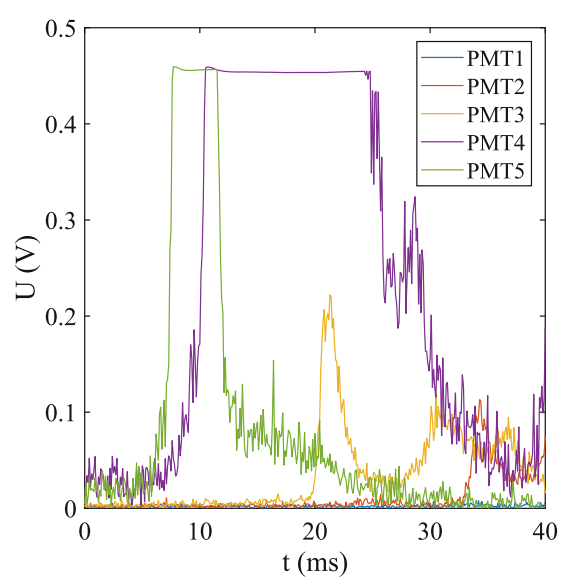

(b) $\tau_{\mathrm{WT} 1}=100 \mathrm{~ms}, \tau_{\mathrm{WT} 2}=540 \mathrm{~ms}$

Fig. 8 Output-signal of PMTs

As shown in Fig. 3, PMTs are used to detect the ignition event at five different axial positions. Figure 8 shows two exemplary output signals of the PMTs. The PMTs detect the light emission of the flame due to auto-ignition. The time of ignition is assumed to be the time when the voltage signal of a certain PMT reaches the threshold of 0.45 V. In Fig. 8a the PMT signal displays an output, where a combustion event is detected by all PMTs, while in Fig. 8 b combustion event was only detected by PMT4 and PMT5. Although there is a peak in the signal of PMT3, this is not interpreted as an ignition event at this position, since it does not reach the threshold of $0.45 \mathrm{~V}$. It rather can be interpreted as an ignition event close to the position of PMT3 causing some light emission entering the PMT3. As a criteria for auto-ignition only the first PMT signals are considered as actual auto-ignition events since in this paper, it is not aimed for a fuel stratification. Starting from the first ignition it is considered that the remaining PMTs only detect a deflagrative propagating flame front.

Figure 9 illustrates the ignition events at different positions in the combustor for different wastegate timings $\tau_{\mathrm{WT} 1}$ and $\tau_{\mathrm{WT} 2}$. Every node at the $x$-axis is representative 


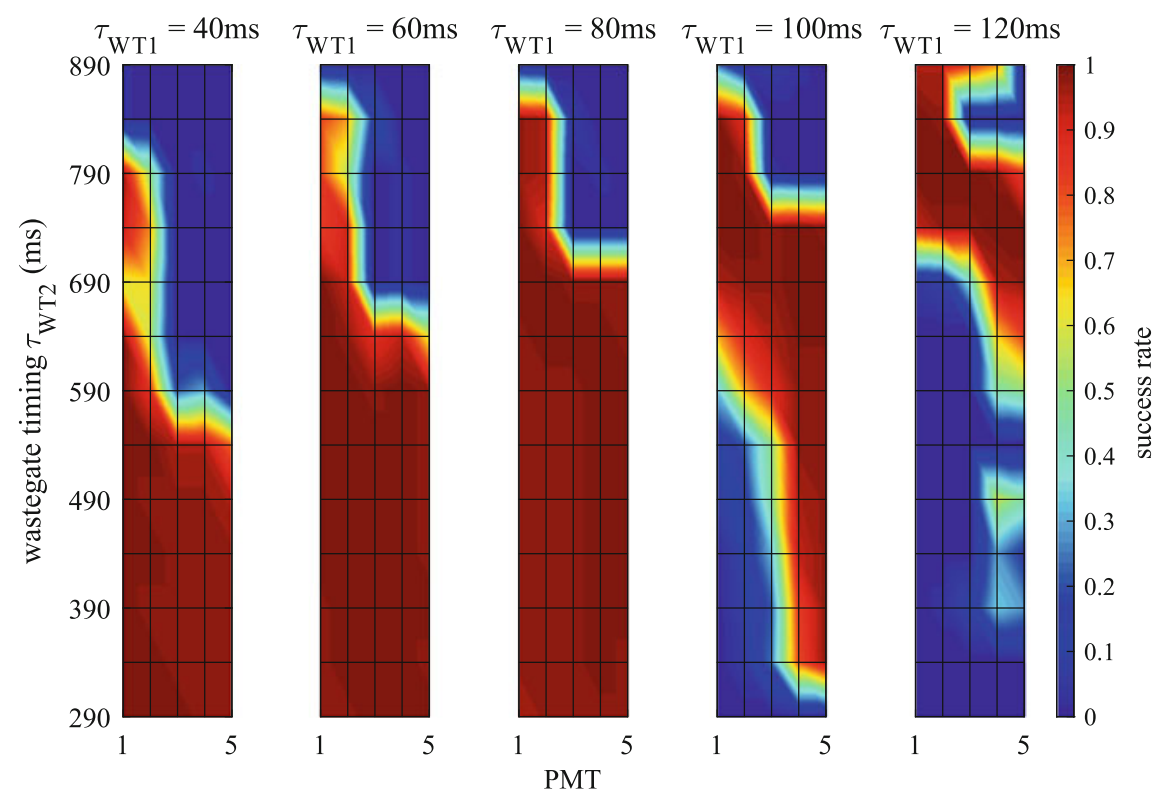

Fig. 9 Investigation on the impact of the purging time on the success rate on every single PMT by varying $\tau_{\mathrm{WT} 1}$ and $\tau_{\mathrm{WT} 2}$

for one PMT, while the $y$-axis represents different timings for switching from bypass into the combustor. The colorbar represents the success rate of auto-ignition whereby 40 cycles where evaluated in total for every combination of tested wastegate timings. A success rate of 1 means that the PMT detected an ignition event in every single cycle. The blue areas, representing a value of 0 , show that no ignition could be detected, respectively.

It is apparent that for relatively high purging times ( $\left.\tau_{\mathrm{WT} 2} \leq 540 \mathrm{~ms}\right)$ and $40 \mathrm{~ms} \leq$ $\tau_{\text {WT1 }} \leq 80 \mathrm{~ms}$, every single PMT has a success rate of 1 . It can be assumed that the entire quartz tube is filled with a flammable mixture as visualized in Fig. 10 case B. Thus, this regime contains a periodic auto-ignition event that induces a combustion process at all observed axial positions in the combustor.

Increasing $\tau_{\mathrm{WT} 1}$ results in the injected fuel package traveling further downstream before the flow is stopped due to the closing of WG1 (see Fig. 10). Thus, the ignition event is shifted more and more into the exhaust tube. Therefore, an increase to $\tau_{\mathrm{WT} 1}=$ $100 \mathrm{~ms}$ reduces the detected ignition events at the first three PMTs drastically (Fig. 10 case D). For $\tau_{\mathrm{WT} 1}=120 \mathrm{~ms}$, no PMT detects a stable combustion for $\tau_{\mathrm{WT} 2}<690 \mathrm{~ms}$ as the success rate is zero at every position since the entire burnable mixture has been moved outside of the quartz tube, where the combustion event cannot be detected by the PMTs (Fig. 10 case E). This observation demonstrates the ability to control the spatial fuel distribution by using actively controlled wastegates. 


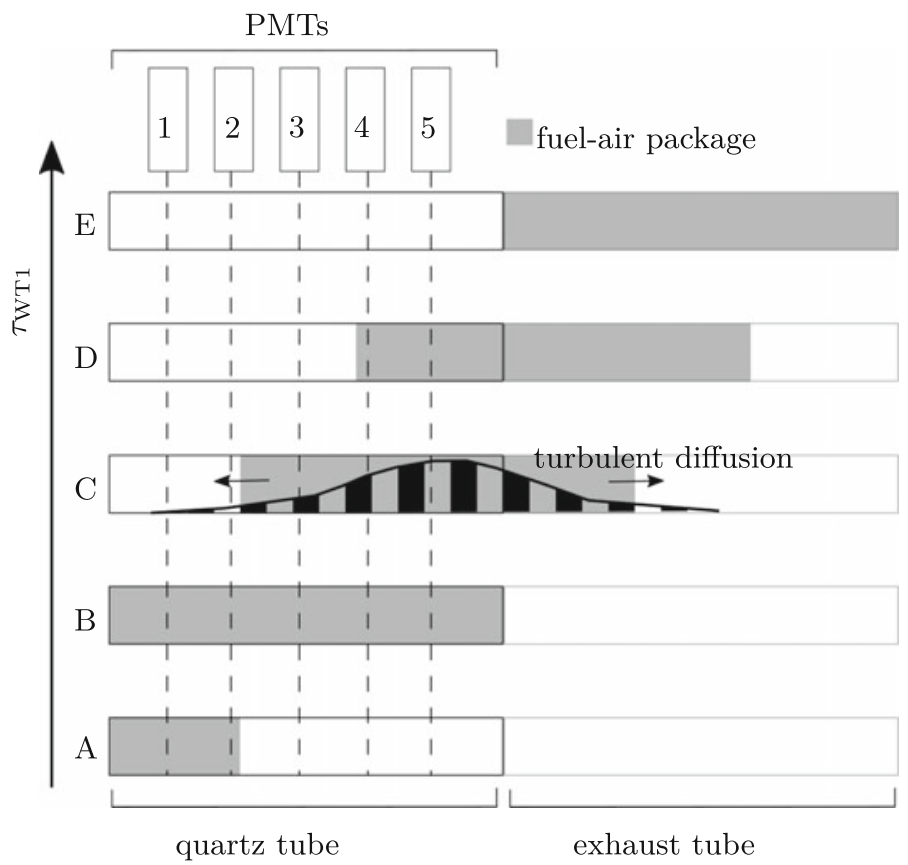

Fig. 10 Position of the fuel-air package in the combustor for an increasing $\tau_{\mathrm{WT} 1}$ value

For an increased $\tau_{\mathrm{WT} 2}$ and a constant $\tau_{\mathrm{WT} 1}$, no ignition event can be detected at PMTs 3-5. A presumption for this effect is that due to small periods of purging, hot combustion products remain in the combustor due to recirculation areas near the injection geometry and cause contact burning when the next fuel package is injected. Thus, a auto-ignition fails and the combustion is only detected by the first PMTs since there is no time for the fuel-air mixture to travel downstream before ignition. This phenomenon can be observed when $\tau_{\text {WT2 }}$ exceeds a certain threshold that equals the time that is needed to purge all the exhaust gases that have entered the injection geometry and the supply line due to the increased pressure in the combustor after the combustion event.

This threshold for $\tau_{\mathrm{WT} 2}$, where the success rate changes from 1 to 0 for a constant $\tau_{\text {WT1 }}$, is shifted upwards by increasing $\tau_{\text {WT1 }}$. As mentioned earlier, increasing $\tau_{\text {WT1 }}$ causes the burnable mixture to travel further downstream before the auto-ignition takes place. This leads to a smaller amount of hot exhaust gases in the upstream part of the combustor. Thus, a shorter time is needed to purge the line.

By further increasing $\tau_{\mathrm{WT} 2}$, a second characteristic of the SEC test rig is visible. When the preheated air flow is guided through the bypass, the temperature in the combustor decreases. The more time the air flow is guided through the combustor, the higher the temperature gets. Since the ignition delay time of DME is still sensitive to the mixing temperature as shown in $[1,10]$, a small value of $\tau_{\mathrm{WT} 1}$ and a large 

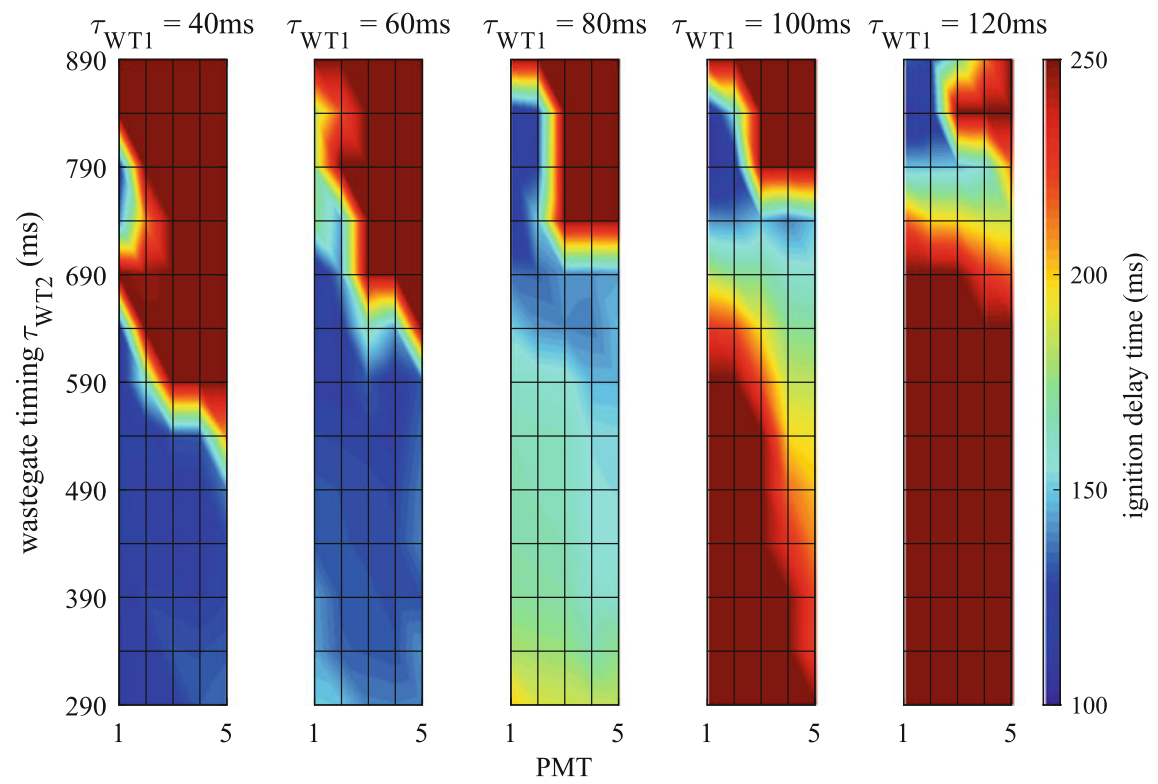

Fig. 11 Investigation of the impact of the purging time on the ignition delay time on every single PMT by varying $\tau_{\mathrm{WT} 1}$ and $\tau_{\mathrm{WT} 2}$

value of $\tau_{\text {WT2 }}$ causes the ignition delay time to exceed the cycle duration. Therefore, no combustion event is detected by the PMTs. Depending on the purging time the temperature in the combustor varies significantly. A higher purging time causes an increase in temperature but is also the limiting factor for higher frequencies. Low purging times cause burnt gas to remain in the combustor causing an uncontrolled ignition. This proves that the purging time is a decisive parameter in order to achieve an increased homogeneity of the auto-ignition process.

The mean ignition delay time is measured as the time span from the start of injection to the detection until combustion event. The local ignition delay time varies from 100 to $250 \mathrm{~ms}$. When no combustion event is detected, the ignition delay time exceeds the value of $250 \mathrm{~ms}$ (see Fig. 11).

The velocity over time shown in Fig. 5 implies that an increase in $\tau_{\text {WT1 }}$ leads to an increased time span in which the mixture is exposed to high turbulence. Turbulent diffusion causes mixing of the flammable mixture with the surrounding air at the bounds of the fuel-air package (see Fig. 10 case C). This leads to a decrease in the gradient of the equivalence ratio with increasing $\tau_{\mathrm{WT1}}$. Thus, the observed ignition delay time increases with increasing $\tau_{\mathrm{WT} 1}$, which is contradicting the wish for a specifically shaped profile of fuel stratification. Increasing $\tau_{\text {WT2 }}$ induces a slight decrease in the ignition delay time. 


\section{Conclusion and Outlook}

The SEC process was investigated under atmospheric pressure conditions using a modified test rig. Wastegates, which replaced the former used fluidic switch and valve heads, were used to obtain the influence of purging time and to find improved conditions for successfully reducing the ignition delay time at atmospheric conditions. It has been shown that actively controlled wategates enable precise control of the fuel distribution. It has been proved that the purging time has a decisive impact on the performance of a shockless explsoion combustor. New parameters were found that can be utilized as input data for closed-loop control in order to optimize the spatial fuel distribution which is essential for achieving a homogeneous auto-ignition.

The obtained data showed that the auto-ignition itself is a complex process with a high number of variables. This work gives a detailed look to the sensitivity of the SEC process to the switching timings of the wastegates as an important control parameter.

The next step is to significantly decrease the ignition delay times. Therefore, experimental investigations in an intermediate pressure test rig are planned. A decrease in ignition delay time would lead to higher firing frequencies that are needed to realize resonant operation. A new stainless steel combustion chamber has been designed, where ionization probes will be used for flame detection at elevated pressures.

Acknowledgements The authors gratefully acknowledge support by the Deutsche Forschungsgemeinschaft (DFG) as part of Collaborative Research Center SFB 1029 "Substantial efficiency increase in gas turbines through direct use of coupled unsteady combustion and flow dynamics" on project A01.

\section{References}

1. Bobusch, B.C., Berndt, P., Paschereit, C.O., Klein, R.: Shockless explosion combustion: an innovative way of efficient constant volume combustion in gas turbines. Combust. Sci. Technol. 186(10-11), 1680-1689 (2014)

2. Stathopoulus, P., Vinkeloe, P., Paschereit, C.O.: Thermodynamic evaluation of constant volume combustion for gas turbine power cycles. In: 11th International Gas Turbine Congress, Tokyo, Japan, pp. 15-20 (2015)

3. Roy, G.D., Frolov, S.M., Borisov, A.A., Netzer, D.W.: Pulse detonation propulsion: challenges, current status, and future perspective. Prog. Energy Combust. Sci. 30(6), 545-672 (2004)

4. Lu, F.K., Braun, E.M.: Rotating detonation wave propulsion: experimental challenges, modeling, and engine concepts. J. Propul. Power 30(5), 1125-1142 (2014)

5. Yao, M., Zheng, Z., Liu, H.: Progress and recent trends in homogeneous charge compression ignition (HCCI) engines. Prog. Energy Combust. Sci. 35(5), 398-437 (2009)

6. Stanglmaier, R.H., Roberts, C.E.: Homogeneous charge compression ignition (HCCI): benefits, compromises, and future engine applications. Technical report, SAE Technical Paper (1999)

7. Meyer, J.W., Cohen, L.M., Oppenheim, A.K.: Study of exothermic processes in shock ignited gases by the use of laser shear interferometry. Combust. Sci. Technol. 8(4), 185-197 (1973)

8. Cai, L., Pitsch, H.: Tailoring fuels for a shockless explosion combustor. In: Active Flow and Combustion Control 2014, pp. 299-315. Springer (2015) 
9. Reichel, T.G., Schäpel, J.-S., Bobusch, B.C., Klein, R., King, R., Paschereit, C.O.: Shockless explosion combustion: experimental investigation of a new approximate constant volume combustion process. J. Eng. Gas Turbines Power 13(2), 021504 (2017)

10. Berndt, P.: On the use of the hll-scheme for the simulation of the multi-species euler equations. In: Finite Volumes for Complex Applications VII-Elliptic, Parabolic and Hyperbolic Problems, pp. 809-816. Springer (2014)

11. Bobusch, B.C.: Fluidic devices for realizing the shockless explosion combustion process (2015) 